\title{
Unidirectional solidification of Tb-Fe giant magnetostrictive alloys under microgravity conditions
}

\author{
微小重力環境下での $\mathrm{Tb}-\mathrm{Fe}$ 超磁歪合金の一方向凝固
}

\author{
Shinya KANO, Yuuichi HASHIMOTO, Yoshimasa TAKEDA, Kazuyoshi ISHIDA and \\ Yoshihito MATSUMURA \\ Department of Applied Physics, Tokai University \\ 1117 Kitakaname, Hiratsuka, Kanagawa, 259-1292, Japan \\ TEL:x81-463-58-1211(EX.4909)FAX:x81-463-58-9461e-mail:ncc1701d@keyaki.cc.u-tokai.ac.jp \\ Toshiro KUJI \\ School of High Technology for Human Welfare TOKAI University \\ 317 Nishino, Numazu-city, Shizuoka 410-0395, JAPAN \\ TEL:x81-55-968-1211(EX2302)FAX:x81-55-968-1155 e-mail:tkuji@wing.ncc.u-tokai.ac.jp \\ ( Received 31, January 2003 Accepted 7, May 2003)
}

\begin{abstract}
$\mathrm{TbFe}_{2}$ grain alignment in Tb-Fe alloys solidification under microgravity $(\mu \mathrm{G})$ and terrestrial gravity $(1 \mathrm{G})$ was investigated. The microgravity was obtained by free fall in drop tower facility at the Japan Microgravity Center (JAMIC). $\mathrm{TbFe}_{1.83}$ alloy of 1 gram was prepared for unidirectional solidification under microgravity environment. The samples were melted just before drop and solidified by contact chill against a sample under the microgravity during dropping. The microstructure of $\mu \mathrm{G}$ sample was columnar and $\mathrm{TbFe}_{2}$ grains were strongly aligned along the thermal gradient. In $1 \mathrm{G}$ sample, the aligned microstructure was not obtained. The alloy composition was measured by EDX. The $\mathrm{TbFe}_{3}$ phase was observed in $1 \mathrm{G}$ sample, and no $\mathrm{TbFe}_{3}$ phase was observed in $\mu \mathrm{G}$ sample, caused by reduction of thermal convection in microgravity environment. In $\mu \mathrm{G}$ sample, the (111) orientation of $\mathrm{TbFe}_{2}$ grains was obtained. The magnetostriction in parallel direction to the thermal gradient was larger than those in perpendicular direction in $\mu \mathrm{G}$ and $1 \mathrm{G}$ sample. The magnetostriction of $\mu \mathrm{G}$ sample in parallel direction to the thermal gradient was larger than that for $1 \mathrm{G}$ sample caused by microstructure.
\end{abstract}

Keywords : Giant magnetostrictive material, $\mathrm{TbFe}_{2}$, microgravity, unidirectional solidification, microstructure

\section{INTRODUCTION}

$\mathrm{TbFe}_{2}, \mathrm{SmFe}_{2}$ や Terfenol-D といった超磁歪合金は、室 温で大きな磁歪量を示すことから応用に向けて広く研 究されている。1,2 現在これらの超磁歪合金は、ソナー やトルクセンサなどに応用されているが広く応用され てはいない。しかし最大磁歪量や磁歪感受率などの磁歪 特性が向上すれば精密機械制御やマイクロマシンのア クチュエータなどの電気一機械エネルギー変換分野に 広く応用が期待される。 $\mathrm{TbFe}_{2}$ の結晶構造はラーベス構 造であり、磁場を<111>に印加したときに最大の磁歪量 を示す。そのため、磁歪量向上には結晶の向きを揃える ことが重要になる。一般に結晶の向きを揃えるためにブ リッジマン法、チョクラルスキー法やゾーンメルティン
グ法などが用いられるが、時間と手間がかかる。 ${ }^{3-12} ま$ た、 $\mathrm{TbFe}_{2}$ は包晶反応を経て凝固するので、凝固時に $\mathrm{TbFe}_{3} 、 \mathrm{TbFe}_{2} 、 \mathrm{~Tb}$ の 3 相に分離し均一な組織を得ること が難しい。

ところで、最近、微小重力環境が材料工学の分野で注 目されている。微小重力環境下では熱対流が抑制される。 そのため温度勾配が地上重力よりも乱れにくいことが 期待できる。そのため、凝固途中の組織が対流の影響を 受け難く、地上で行なう一方向凝固よりも方向の揃った 組織が得られる可能性がある。また、微小重力環境下で は大きな過冷却が期待できる。包晶反応温度以下の過冷 却状態から凝固を開始できれば包晶反応を起こさずに 凝固させることが期待できる。そこで、本研究では微小 
重力環境下で超磁歪合金の一方向凝固を試み、地上重力 下で同様にして作製したものとの差異を比較する。

\section{EXPERIMENTAL}

微小重力環境下での実験は(株)地下無重力実験センタ 一(JAMIC)で行った。一方向凝固実験装置を落下カプセ ルに搭載し $490 \mathrm{~m}$ 自由落下させた。これにより 10 秒間 $10^{-4} \mathrm{G}$ の微小重力環境を得た。試料は、アーク溶解炬で 作製した $\mathrm{TbFe}_{1.83}$ 合金を、一辺 $5 \mathrm{~mm}$ 角に切り出し質量 を $1 \mathrm{~g}$ に揃えて使用した。試料組成は、加熱中の酸化に よって $\mathrm{Tb}$ が減少するため、あらかじめ $\mathrm{Tb}$ リッチにした ものを用いた。試料表面は\#2000 の耐水研磨紙で研磨し 酸化膜を除去した。Figure 1 に一方向凝固装置の模式図 を示す。装置内をロータリーポンプとターボ分子ポンプ で $1.0 \times 10^{-3} \mathrm{~Pa}$ 以下まで真空排気し、0.12 MPa の $\mathrm{Ar}$ 雰囲 気に置換した。実験中は $\mathrm{Ar}$ ガスを $20 \mathrm{sccm}$ で流しつづけ ることにより、装置内に不純ガスが混入することを防い だ。また、真空排気中に試料を $500^{\circ} \mathrm{C}$ 以下まで予加熱し 脱ガスを行った。試料温度は赤外放射温度計で計測した。

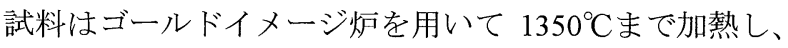
完全に融解したことを確認してから落下カプセルを落 下させた。一方向凝固は、試料の上部から銅製の冷却チ ルを接触させて行った。冷却チルの接触は、落下時の微 細な振動を避けるためカプセル落下の 2 秒後以降に行っ た。試料は BN ブロック上の皿状石英るつぼに乗せた。 これにより試料下部からの熱の放出を抑え、熱流が試料 の下部から上部へと一方向に向くことが期待できる。

金属組織は光学顕微鏡と走査電子顕微鏡 $(\mathrm{SEM})$ で観察 した。組成分析はエネルギー分散型 $\mathrm{X}$ 線分光法(EDX)を 用いた。結晶構造は X 線回折法(XRD)を用いて同定した。 磁歪量はストレインゲージ法を用いて測定した。保磁力 は試料振動型磁力計を用いて測定した。なお、熱勾配に 対する各測定方向の関係を Fig. 2 に示す。

\section{RESULTS AND DISCUSSION}

Figure 3 は $\mu \mathrm{G}$ 試料と $1 \mathrm{G}$ 試料の熱勾配に平行な断面の 反射電子像である。 $\mu \mathrm{G}$ 試料は灰色と白の 2 相に、 $1 \mathrm{G}$ 試 料は暗い死色と灰色と白の 3 相に別れているのが確認で きた。各相を $\mathrm{EDX}$ で調べたところ $\mu \mathrm{G}$ 試料は $\mathrm{Tb}$ 相と $\mathrm{TbFe}_{2}$ 相の 2 相に、1G 試料は $\mathrm{Tb}$ 相、 $\mathrm{TbFe}_{2}$ 相と $\mathrm{TbFe}_{3}$ 相 の 3 相に分かれているのがわった。Hansen らはマクロ偏 析が熱対流によって甚だしくなることを報告している。 $13 \mu \mathrm{G}$ 環境では $1 \mathrm{G}$ 環境に比べて熱対流が格段に減少す るため、偏析が少なく $\mathrm{TbFe}_{3}$ 相がなかったと考えられる。 $\mu \mathrm{G}$ 試料には熱勾配に沿った柱状組織があった。この柱 状組織は試料の厚み全部に渡っていて、個々の結晶粒の 太さも 20〜30 $\mu \mathrm{m}$ でほぼ一定であった。また、柱状組織 の方向のばらつきは $3^{\circ}$ 以内で非常によく揃っていた。 Bonino $ら^{3}$ は一方向鋳造で作製した $\mathrm{Tb}_{0.3} \mathrm{Dy}_{0.7} \mathrm{Fe}_{2}$ 合金の 組織のばらつきが $12^{\circ}$ 以内であったことを報告してい
る。対して $1 \mathrm{G}$ 試料の組織は、全体的には熱勾配に沿っ ているが平行に揃っておらず、チル接触面から放射状に 伸びていた。また、組織の結晶粒の太さは、試料上部(チ ル接触面側)では数 $\mu \mathrm{m}$ で試料下部(石英るつぼ側)では 30 〜50 $\mu \mathrm{m}$ と徐々に太くなっていた。これは、試料上部は 冷却チルが接触したときに急冷されて凝固速度が速く、

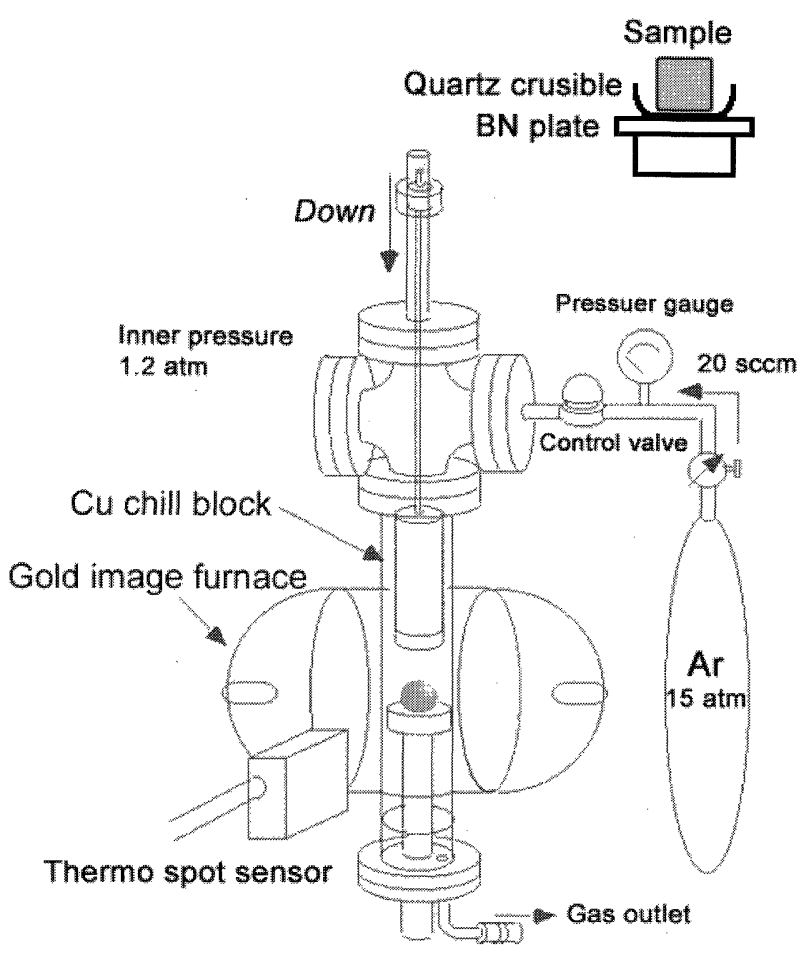

Fig.1. Schematic diagram of the unidirectional solidification apparatus.

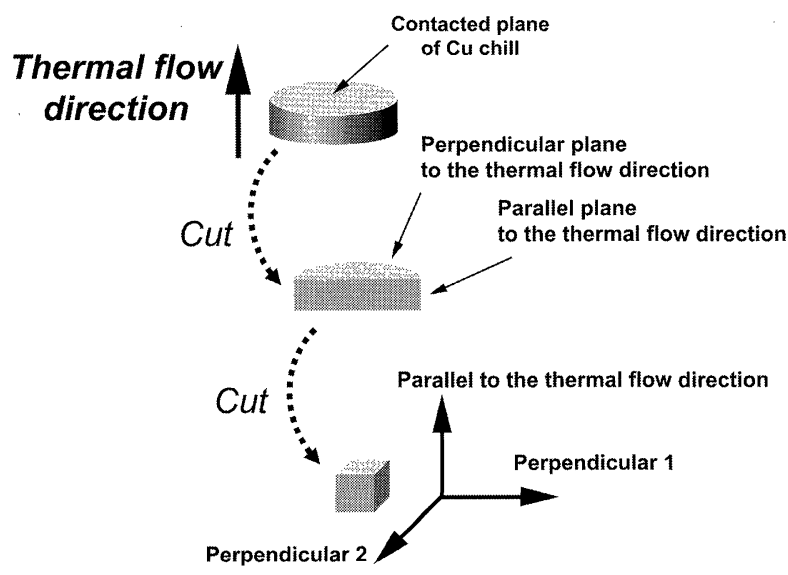

Fig.2. Schematic diagram of mesurments directions. 
試料下部に向からにつれて凝固潜熱に上って凝固速度 が痋くなっていったためだと考えられる。

Figure 4 に各断面の $\mu \mathrm{G}$ 試料と $1 \mathrm{G}$ 試料のX線回折パ夕 ーンを示吉。どちらの試料にも $\mathrm{TbFe}_{2}$ と $\mathrm{TbO}_{\mathrm{x}}$ の回折ピー クが見られたが、 $\mathrm{TbFe}_{3}$ のピークは $1 \mathrm{G}$ 試料にの多見られ
た。 $\mu \mathrm{G}$ 試料の熱勾配に珜直な断面と平行な断面党比較 すると、垂直な断面には $\mathrm{TbFe}_{2} の(222)$ と(333)のピークが 見られた。この結果加ら $\mu \mathrm{G}$ 試料の熱勾配に沿った柱状 組織は(111)に向いていると考えられる。1G 試料では、 熱勾配に平行な断面の(224)ピークは垂直な断面よりも

\section{$\mu G$}

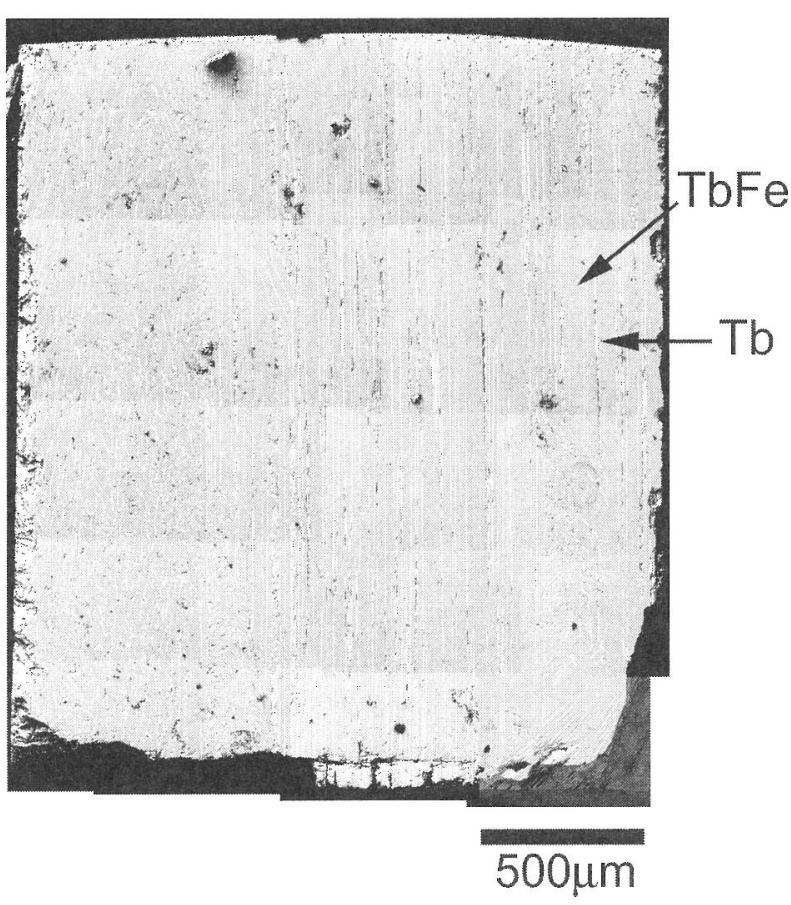

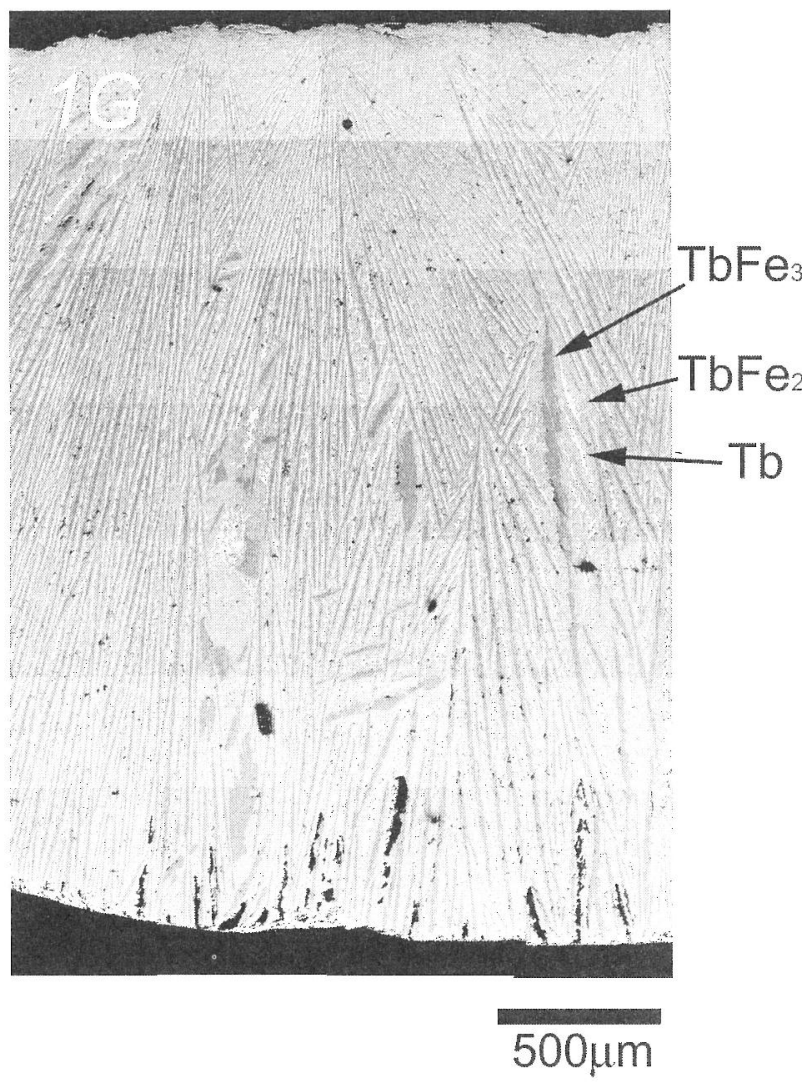

Fig. 3: Backscattering electron image of $\mu \mathrm{G}$ sample and $1 \mathrm{G}$ sample in parallel to the gradient of thermal flow.

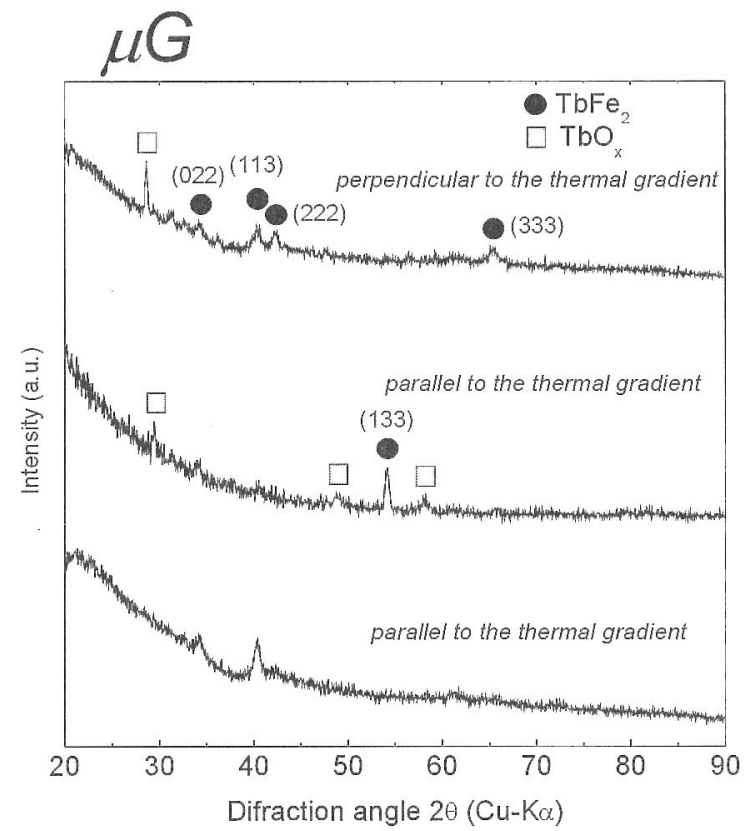

$1 G$

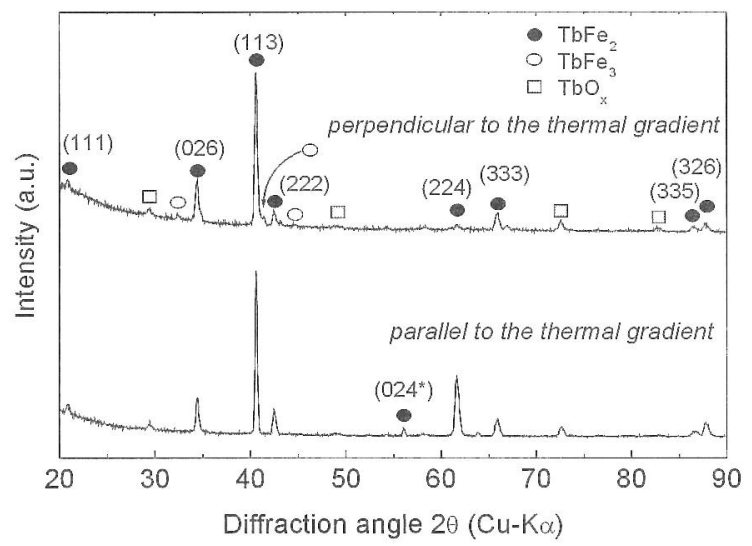

Fig.4. X-ray diffraction patterns of $\mathrm{mG}$ sample and $1 \mathrm{G}$ sample in parallel and perpendicular plane to the thermal gradient. 


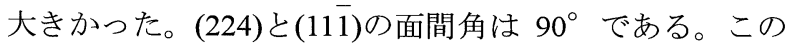
ことより、1G 試料は熱勾配に(111)がそれほど向いてい ないと考えられる。Verhoven らと Clark らは TbDyFe 合

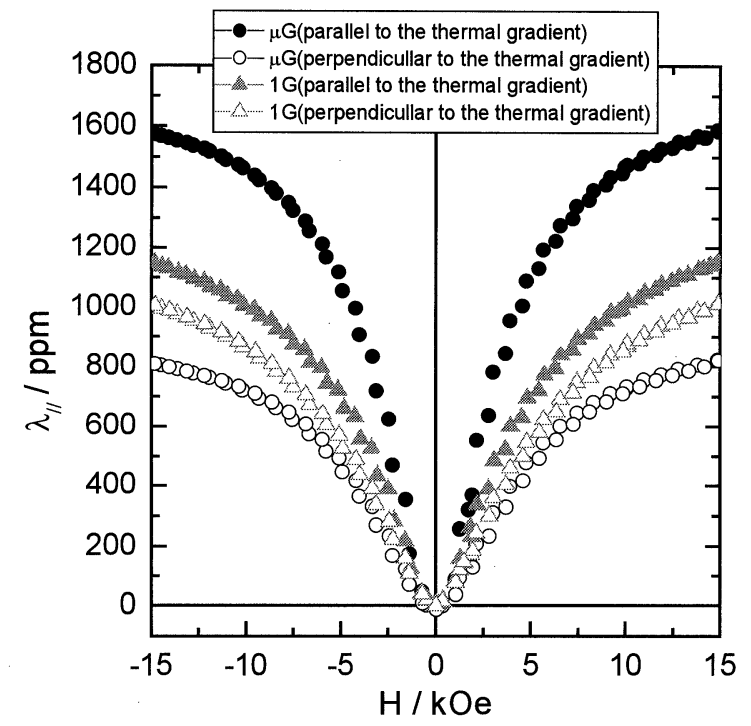

Fig.5. Magnetostriction characteristics of $\mu \mathrm{G}$ sample and $1 \mathrm{G}$ sample in parallel direction and perpendicular direction to the thermal gradient.

金の優先成長方向は<112>であり、板状のデンドライト 組織をとることを報告している。9,11 XRD の結果は過 去の研究と良い一致を示している。 ${ }^{8,10}$

Figure 5 は $\mu \mathrm{G}$ 試料と $1 \mathrm{G}$ 試料の熱勾配方向と垂直な方 向の磁歪量を示している。どちらの試料も熱勾配方向の 磁歪量が垂直な方向の磁歪量よりも大きい。XRD の測定 結果から、 $\mu \mathrm{G}$ 試料の熱勾配に良く揃った柱状組織は (111)に向いていて、1G 試料の緩く熱勾配に揃った組織 も(111)に向いていることがわかっている。どちらの試料 も熱勾配に(111)が向いているためだと考えられる。また、 測定方向による磁歪量の差は $\mu \mathrm{G}$ 試料の方が $1 \mathrm{G}$ 試料より も大きい。これは $\mu \mathrm{G}$ 試料の熱勾配に良く揃っている柱 状組織が<111>に向いているために、磁歪の異方性が $1 \mathrm{G}$ 試料よりも大きいためだと考えられる。また、組織の揃 った部分だけを切り出した他の試料は $8 \mathrm{kOe}$ 印加時に 1700 ppm の磁歪量を示した。

Table 1 は $\mu \mathrm{G}$ 試料と $1 \mathrm{G}$ 試料の熱勾配に平行な方向と 垂直な方向の保磁力を示している。 $\mu \mathrm{G}$ 試料の保磁力は どの測定方向でも $1 \mathrm{G}$ 試料の保磁力よりも小さかった。

これは $\mu \mathrm{G}$ 試料には $\mathrm{TbFe}_{3}$ 相が存在しないためだと考 えられる。また、 $\mu \mathrm{G}$ 試料も $1 \mathrm{G}$ 試料も熱勾配方向の保磁 力が他の 2 方向よりも小さい事がわかった。これは熱勾 配に揃つた組織の結晶磁気異方性のためだと考えられ る。
Table 1 . The coercivity of $\mu \mathrm{G}$ sample and $1 \mathrm{G}$ sample in parallel direction and perpendicular direction to the thermal gradient.

\begin{tabular}{ccc}
\hline Measurements direction & \multicolumn{2}{l}{ Coercivity / Oe } \\
\hline & $1 \mathrm{G}$ & $\mu \mathrm{G}$ \\
\hline Parallel & 283 & 190 \\
Perpendicular 1 & 356 & 198 \\
Perpendicular 2 & 350 & 202 \\
\hline
\end{tabular}

\section{CONCLUSION}

微小重力環境下での $\mathrm{TbFe}_{1.83}$ 合金の一方向凝固を行っ た。 $\mu \mathrm{G}$ 試料の金属組織は熱勾配に良く揃った柱状構造 であった。1G 試料の金属組織は熱勾配にあまり揃って いない柱状構造が見られた。一般に微小重力環境下では 熱対流が抑制される。これにより融液の運動が抑制され、 また熱勾配の乱れが減少したと考えられる。 $\mu \mathrm{G}$ 試料は $1 \mathrm{G}$ 試料よりも熱勾配の乱れが小さく、凝固時の金属組 織の成長が一定だったので熱勾配に良く揃った組織が できたと考えられる。 $\mu \mathrm{G}$ 試料と $1 \mathrm{G}$ 試料の金属組織を $\mathrm{EDX}$ で調べたところ、 $\mu \mathrm{G}$ 試料の柱状組織には $\mathrm{TbFe}_{3}$ 相 がないことがわかった。XRD で結晶方位を調べたところ $\mu \mathrm{G}$ 試料の熱勾配に揃った柱状組織は(111)に向いている ことがわかった。 $\mu \mathrm{G}$ 試料と $1 \mathrm{G}$ 試料の磁歪量を測定した ところ、どちらの試料も熱勾配方向の磁歪量が大きかっ た。これは、組織が熱勾配に沿っているためだと考えら れる。また測定方向の違いによる磁歪量の差は $\mu \mathrm{G}$ 試料 の方が大きかった。 $\mu \mathrm{G}$ 試料の柱状組織が熱勾配に良く 揃っていて、結晶粒が<111>を向いているためだと考え られる。保磁力は $\mu \mathrm{G}$ 試料の方が $1 \mathrm{G}$ 試料よりもどの測定 方向においても小さかった。これは $\mu \mathrm{G}$ 試料には $\mathrm{TbFe}_{3}$ 相が存在しないためだと考えられる。また、どちらの試 料も熱勾配方向の保磁力は他の方向に比べて小さかっ た。これは、熱勾配に沿った組織の結晶磁気異方性のた めだと考えられる。

\section{ACKNAWLEDGMENTS}

この研究は(財)宇宙環境利用推進センター(JSUP), (財) 新エネルギー産業技術総合開発機構(NEDO)“高性能磁性 材料創製技術の研究開発” および東海大学未来科学技術 共同研究センター “エコテクノロジープロジェクト” において遂行されたものである。また、研究に多大な支 援をして頂いた(独)産業技術総合研究所奥谷猛博士、皆 川秀紀博士、JSUP 鎌田恵司氏(現 侏セテック)、東海 大学竹内光明氏に感謝心よりします。

\section{REFERENCES}

${ }^{1}$ A.E. Clark, Magnetostrictive rare earth- $\mathrm{Fe}_{2}$ compounds, in Ferromagnetic Materials Vol. 1, (North-Holland Publishing Company, 1980), pp. 531-581. 
2 J.P. Teter, O.D. McMasters and A.E. Clark, J. Appl. Phys. 61(8), pp. 3787-3789, (1987).

${ }^{3}$ O. Bonino, P. De. Rango, and R. Tournier, J. of Magn. Magn. Mater., 212, pp. 225-230, (2000).

${ }^{4}$ Y.J. Bi, J.S. Abell, and A.M.H. Hwang, J. of Magn. Magn. Mater., 99, pp. 159-166, (1991).

${ }^{5} \mathrm{Wu}$. Mei, T. Umeda, S. Zhou, and R. Wang, J. of Alloys and Compounds, 224, pp. 76-80, (1995).

${ }^{6}$ Wu. Mei, T. Okane, T. Umeda, and S. Zhou, J. of Alloys and Compounds, 248, pp. 151-158, (1997).

${ }^{7} \mathrm{Wu}$. Mei, M. Yoshizumi, T. Okane, and T Umeda, J. of Alloys and Compounds, 258, pp. 34-38, (1997).

${ }^{8}$ O.D. McMasters, J.D. Verhoeven, and E.D. Gibson, J. of Magn. Magn. Mater. 54-57, pp. 849-850, (1986).
9 J.D. Verhoeven, E.D. Gibson, O.D. McMasters, and H.H. Baker, Metall. Trans. A 18A, pp. 223-231, (1987).

${ }^{10}$ J.D. Verhoeven, E.D. Gibson, O.D. McMasters, and J.E. Ostenson, Metall. Trans. A 21A, pp. 2249-2255, (1990).

11 A.E. Clark, J.D. Verhoven, O.D. McMasters, and E.D. Gibson, IEEE Trans. on Magn. 22, pp. 973-975, (1986).

${ }^{12}$ W. Je. Park, J. Chul. Kim, B. June. Ye, and Z. Hyoung. Lee, J. of Crystal Growth, 212, pp. 283-290, (2000).

${ }^{13}$ G. Hansen, A. Hellawell, S.Z. Lu, and R.S. Steube, Metall. and Mater. Trans. A, 27A, pp. 569-581, (1996).

SAS Award (Prize of Innovation) was given to this paper presented as Poster Presentation at the 2002 SAS Intelligent Symposium. 